\title{
El fenómeno del conejo malo "Bad Bunny": ¿reivindicación de las masculinidades o reproducción de la misoginia?
}

\author{
The "Bad Bunny" phenomenon of the bad rabbit: vindication of \\ masculinities or reproduction of misogyny?
}

Keylor Robles Murillo*

\section{Resumen:}

En este artículo se analiza el «fenómeno del conejo», originado a partir de la figura de Bad Bunny, cantante de trap latinoamericano. En primer lugar, se incluye una breve reseña del surgimiento de este género musical en América Latina junto con la biografía del artista. En segundo lugar, se detalla la metodología definida en el proceso investigativo. Las técnicas elegidas corresponden al Análisis Crítico de Discurso (ACD) y la netnografía. La muestra se conforma por cuatro videos del artista y sus canciones producidas entre el 2016 al 2020. En los resultados se discute alrededor de la reivindicación de las masculinidades, subversión de los mandatos de género y la reproducción de la misoginia. Se concluye que los discursos del cantante en cuanto al género son contradictorios, pues a pesar de trasgredir algunos mandatos socioculturales impuestos por la masculinidad hegemónica, continúa reproduciendo universos discursivos que violentan a las mujeres.

Palabras clave: Música, Feminismo, Sexismo, Discurso, Mujer.

\begin{abstract}
:
This article analyzes the "phenomenon of the rabbit", originated from the figure of Bad Bunny, a Latin American trap singer. Firstly, a brief review of the emergence of this musical genre in Latin America is included along with the artist's biography. Secondly, the methodology defined in the investigative process is detailed. The chosen techniques correspond to Critical Discourse Analysis (ACD) and netnography. The sample conforms to four videos of the artist and his songs produced between 2016 and 2020. In the results, he discusses the demands of masculinities, subversion of the mandates of gender and the reproduction of misogyny. It is concluded that the speeches of the singer in terms of the genre are contradictory, although they may transgress some socio-cultural mandates imposed by hegemonic masculinity, continuing to reproduce discursive universes that violate women.
\end{abstract}

Keywords: Music, Feminism, Sexism, Discourse, Women.

*Bachiller en Trabajo Social, Universidad de Costa Rica (UCR). Tesiario de licenciatura en Trabajo Social, UCR. Enseñanza del Castellano y la Literatura, UCR. Académico destacado de la Corporación de Estudios Avanzados en Trabajo Social (CEATSO), Chile. robleskeylor@gmail.com 
Revista Punto Género N.․ 15 Junio de 2021

ISSN 0719-0417 / 257-276

Fecha de recepción: Agosto 2020

Fecha de aprobación: Junio 2021

\section{Introducción}

Durante las últimas décadas, la música se ha convertido en un objeto de estudio para las Ciencias Sociales y las Humanidades. Dentro de los abordajes llevados a cabo sobre este producto sociocultural se ha profundizado en la relación de la música con el contexto social, político, geográfico, económico y cultural en que circunscribe su proceso de creación y consumo (Berrocal \& Gutiérrez, 2002). Este tipo de estudios han intentado demostrar que las creaciones humanas no se pueden reducir a aspectos estéticos, de disfrute y placer, ya que tienen un componente social latente que debe identificarse.

A partir de la premisa anterior, algunas autoras y autores han construido propuestas teóricas y metodológicas para el análisis de la música, principalmente de las canciones, debido a que estas refieren a dimensiones particulares del lenguaje. En la revisión llevada a cabo, se encuentran estrategias de análisis enfocadas en aspectos musicales, concernientes a la macroforma y elementos rítmicos-culturales (Manco, 2015); así como se identifican propuestas encaminadas a la inclusión de elementos contextuales y coyunturales, como es el caso de López (2013) y Ramírez (2018).

En el presente artículo, se emplean los aportes de las propuestas enfocadas en las implicaciones de los elementos estructurales y los determinantes sociales en el análisis musical; pues como señalan Berrocal y Gutiérrez (2002), la canción debe percibirse como una intersección entre dos mundos: el musical y el lingüístico, los cuales se entienden desde la sociomusicología y la sociolingüística, respectivamente. Estos autores agregan que en este proceso interseccional se engendra una tarea pedagógica y musical a través de la transmisión de la historia y el legado cultural.

En esta relación, configurada entre la música y la sociedad, las canciones se consolidan en un medio para socializar universos discursivos. De acuerdo con Van Dijk (1999), el discurso refiere a un fenómeno práctico, axiológico, social y cultural que brinda insumos para comprender la utilización discursiva del lenguaje en un contexto determinado, más allá de su percepción como una serie ordenadas de palabras. Este fenómeno puede promover los proyectos ideológicos basados en la opresión y dominación; o bien, expresar un ejercicio de resistencia ante la desigualdad imperante en las sociedades. Sus intenciones se analizan desde categorías como el poder y la acción.

Los discursos, vinculados con las visiones de mundo, sobre el género se encuentran en todos los productos socioculturales: la música, el cine, el arte gráfico y la literatura. Sin embargo, cambian las formas en cómo son tratados. Por un lado, existen discursos sexistas que reproducen y legitiman la violencia sistemática contra las mujeres; por el otro, surgen discursos feministas que abogan por la eliminación de las asimetrías y la reivindicación de una sociedad basada en la justicia social y la equidad. En esta reflexión, se profundizan los discursos predominantes respecto al género en las letras y los vídeos de las canciones del puertorriqueño Bad Bunny. 


\section{Origen del trap latinoamericano}

El trap es un género musical que se originó en la década de los noventa en los suburbios de Atlanta, Estados Unidos (Bravo \& Greco, 2018). Sus influencias musicales se relacionan con elementos rítmicos del hip hop, el rap y la música electrónica de baile. Herrera, Morales \& Salas (2019) manifiestan que en el trap se emplean "sintetizadores (instrumento musical de tipo electrónico), cajas rítmicas, subgraves (subtipo de altavoz), hi-hats de subdivisión binaria o ternaria y modos armónicos menores para darle una estética oscura y triste" (p. 10). Asimismo, se utiliza la Roland TR-808, caja de ritmo programable para lograr los efectos de percusión.

Leclerc y Mella (2018) agrupa la evolución del trap en cuatro momentos. En primer lugar, el Crunk (1 de noviembre de 1991 - 15 de diciembre de 1993), sonido proveniente del sur de Estados Unidos. Es una mezcla del rap con la música electro. El término "crunk" es la unión de las palabras crazy (loco)y drunk (borracho). En segundo lugar, los primeros pasos del trap (16 de diciembre de 1993 - 16 de noviembre de 1999), se identifican los primeros registros del trap. En tercer lugar, trap de exportación (2000 - 2003), logra su reconocimiento en el rap. En cuarto lugar, manifestación del trap (2003 - 2007) se lanza el disco "Trap Muzik" del rapero T.I (Estados Unidos, 1980).

Su nombre proviene del argot anglicista trap house, que se traduce como trapicheo en español, empleado para denominar a los sitios utilizados para almacenar y vender drogas y armas (Fullana, 2018). Lo anterior ha provocado que se asocie a la marginalidad, la ilegalidad y la exclusión por parte de un sector de la sociedad estadounidenses (Bravo, 2018). No obstante, el trap también se ha convertido en un espacio artístico de denuncia frente a la segregación, la violencia institucional, la criminalización, la explotación laboral y la matriz racista que predomina en la cultura en Estados Unidos y que ha sido exacerbada por grupos políticos conservadores.

En América Latina, los primeros artistas en incursionar en el trap fueron Arcángel (Estados Unidos, 1985), Yaga (Puerto Rico, 1974), Mackie (Puerto Rico, 1978), Randy (Puerto Rico, 1983) y De la Ghetto (EEUU, 1984). La primera canción latinoamericana de este género, aunque no se definía como trap, fue Pistolón (2007), de Arcángel, en colaboración con Yaga y Mackie, en la que se habla de un hombre que anda armado y está dispuesto a asesinar a quien le corresponda, solo para mantener su orgullo y virilidad. Platt (2018) agrega que el trap latinoamericano se caracteriza por la incorporación masiva y explícita de elementos o referencias de gran contenido sexual en torno a la imagen y el cuerpo de las mujeres. Existe un matriz en donde se cosifican sistemáticamente.

Algunas investigaciones como Bravo (2018) y Herrera, Morales y Salas (2019), no diferencian el trap latinoamericano del reguetón; como se mencionó, en ambos géneros se alude constantemente a temáticas sexuales. De igual manera, muchos cantantes han lanzado sencillos en ambos ritmos; a su vez, hay canciones que contienen extractos de los dos géneros musicales fusionados. Los cantantes más reconocidos, a nivel comercial, en las industrias del trap y el reguetón son oriundos de los mismos países: Puerto Rico, Colombia y Panamá. Existe consenso en que la disimilitud central es el ritmo, ya que el reguetón es más rápido, mientras que el trap 
es lento en su mayoría, a pesar de que puede recurrir a extractos un poco más movidos.

El auge del trap latinoamericano se generó en el año 2016 a partir de las canciones de los puertorriqueños: Anuel AA (1992), Bad Bunny (1994), Bryant Myers (1994) Brytiago (1992), Darell (1990), Farruko (1991), Jhay Cortez (1993), Lary Over (1995), Miky Woodz (1991), Noriel (1994) y Ozuna (1992). Dentro de esta lista, también se pueden incluir a los colombianos: Karol G (1991) y Maluma (1994), junto al panameño Sech1 (1993), quienes han tenido más producciones en el reguetón. Herrera, Morales \& Salas (2019) adicionan otros artistas latinoamericanos surgidos recientemente en otros países: Amenazzy (República Dominicana, 1995), Kheo (Argentina, 1990) y Pvblo Chill-E (Chile, 2000). Sin embargo, el reconocimiento mundial de ellos no es tan amplio. Uno de los rasgos en común compartidos por la mayoría de los representantes del trap latinoamericano corresponde a que provienen de sectores populares (Bravo, 2018).

\section{Biografía de Bad Bunny}

El mayor exponente actual del trap latino es Bad Bunny, cuyo nombre es Benito Antonio Martínez Ocasio. Nació en 1994 en el pueblo de Vega Baja, en San Juan, Puerto Rico. Su seudónimo artístico lo creó a partir de una foto de la infancia en donde tiene puestas unas orejas de conejo y una expresión de enojo en su rostro (Carrion, 2018). Estudió comunicación audiovisual en la Universidad de Puerto Rico en Arecibo. Dejó su formación universitaria para seguir su carrera musical. Ha lanzado tres álbumes de estudio: X100pre (2018), Oasis (2019) en colaboración con J Balvin (Colombia, 1985), y YHLQMDLG (2020). Ha colaborado con artistas de diferentes géneros y países. En el 2018 fue ganador en la categoría de mejor artista en los Latin American Music Awards. En 2020 se presentó en el Super Bowl con Jennifer López (Estados Unidos, 1969), Shakira (Colombia, 1977) y J Balvin.

De acuerdo con Platt (2018), este artista ha originado el "fenómeno del conejo", también llamado el fenómeno Bad Bunny. Esta autora manifiesta que dicho fenómeno, de carácter social, cultural, musical, mediático y político, logra romper con ciertos estereotipos relacionados a la identidad de género y la construcción de la masculinidad2. En un género musical plagado de machismo hace una década hubiera sido imposible hablar del principal exponente como éste apareciendo en redes sociales y sobre el escenario con un estilo "queer" y tan fluido en términos de género: uñas pintadas de colores subidos, ropa estampada, gafas de mujer y estética natural. (2). En la cita anterior sobresalen dos aspectos que resultan centrales en este artículo: a) la incorporación de las premisas de la teoría queer en sus representaciones artísticas, y b) los discursos sobre las mujeres promovidos en canciones del trap

\footnotetext{
1 Los nombres de estos cantantes son los siguientes: Enmanuel Gazmey Santiago, Benito Antonio Martínez Ocasio, Bryan Robert Rohena, Bryan Cancel Santiago, Osvaldo Elías Castro Hernández, Carlos Efrén Reyes Rosado, Jesús Nieves Cortez, Raymon Guevara, Miguel Ángel Rodríguez Rivera, Luis Emmanuel Oses Noel Santos, Juan Carlos Ozuna Rosado, Carolina Giraldo Navarro, Juan Luis Londoño Arias, Carlos Isaías Morales Williams, José Daniel Betances, Ivo Alfredo Thomas Serue, Pablo Acevedo, respectivamente.

${ }^{2}$ Esta idea nos puede acercar a una disimilitud con el reguetón, sin embargo, no podría afirmarse que representa una diferencia central, pues no es un elemento característico de todo el género musical, sino del artista en mención.
} 
latinoamericano, que se contextualizan en una industria configurada alrededor del sexismo, tanto en sus mensajes como en los exponentes más reconocidos. Para explicar cómo se abordan dichos elementos, se torna fundamental describir el procedimiento metodológico empleado en esta oportunidad.

\section{Antecedentes teóricos}

Para profundizar en los resultados, se conceptualizan dos categorías: género, mandatos de género y masculinidad hegemónica, junto con la definición de la teoría queer. En primer lugar, el género "refiere necesariamente al complejo mundo de lo social. Su uso destaca la interacción de un amplio espectro de instituciones [...] para la producción de los códigos culturales que guían el comportamiento de los hombres y de las mujeres. Se aleja de los determinismos biologicistas" (Araya, 2003, p. 42). Lo anterior, permite dilucidar este concepto como una construcción social dialéctica, que se configura según el contexto sociocultural y los determinantes sociales influyentes.

En el caso de Molina \& Osborne (2008, p. 149) agregan que:

[es] el resultado de asignar una serie de características, expectativas y espacios —tanto físicos como simbólicos- a [los] «hombres» y a [las] «mujeres». Estas características y espacios que van a definir lo femenino frente a lo masculino varían de una sociedad a otra, aunque tienen en común la relación jerárquica que se establece entre uno y otro término primando siempre los valores y espacios de lo masculino.

A partir de lo anterior, el género ha brindado una contribución teórica en el desarrollo de nuevos horizontes epistemológicos, ontológicos y axiológicos al permitir la comprensión de los diversos fenómenos sociales y humanos. Además, ha posicionado en el debate conceptual aspectos relacionados con el poder, la identidad y la estructuración de la vida social. Por tanto, no se restringe a una categoría para denotar las relaciones sociales de jerarquía entre hombres y mujeres, sino que supera el análisis descriptivo de dichas relaciones al profundizar críticamente en las causas constitutivas.

Sumado a la categoría esbozada en los párrafos previos, se ubican los mandatos de género, entendidos como los "estereotipos prescriptivos que se acentúan en los procesos de socialización" (Luna \& Valadez, 2018, p. 68). Dentro de estos se encuentran un conjunto de expectativas diferenciadas para los hombres y las mujeres, las cuales se construyen en contraposición; en otras palabras, lo que es "masculino", por tanto, no es femenino, y viceversa. En el caso de Lagarde (2005), sitúa estos mandatos dentro de la lógica del cautiverio determinada por el arraigamiento del patriarcado, en donde se prohíbe y se sanciona todo aquello que se distancie del cumplimiento de los mandatos.

En segundo lugar, la masculinidad hegemónica se asocia a la heterosexualidad obligatoria y al ejercicio de poder por parte de los hombres. Lo anterior implica una renuncia a todo aquello considerado como "femenino", ya que la validación de la masculinidad proviene de otros hombres (Connell, 1997; Schongut, 2012). Existen una diversidad de masculinidades, no obstante, la hegemónica es aquella que se impone como única alternativa y, a su vez, crea un conjunto de 
arquetipos sobre el significado de ser hombre en una sociedad patriarcal. Demetriou (2001) añade que esta masculinidad tiene dos dimensiones: a) externa: refiere a las relaciones asimétricas entre hombres y mujeres; e b) interna: genera una relación jerárquica entre los hombres.

Una de las propuestas teóricas que plantean una deconstrucción del género y, al mismo tiempo, una resistencia ante la masculinidad hegemónica, es la teoría queer. De acuerdo con Butler (2006), esta teoría se opone a la regulación de la identidad, especialmente en los casos en que dicha identidad se legisla de manera obligatoria. Según Fonseca \& Quintero (2009), "el verbo transitivo queer expresa el concepto de «desestabilizar», «perturbar», «jorobar»; por lo tanto, las prácticas queer se apoyan en la noción de desestabilizar normas" (45). A partir de esta idea, la teoría queer también se opone a las categorías binarias que han predominado para analizar la sexualidad humana: hombre/mujer, masculino/femenino, heterosexual/homosexual, al afirmar que existe una pluralidad que no se encasilla en estas visiones dicotómicas y heteronormadas.

Dentro de esta teoría, cobra relevancia el término "género fluido", empleado por Platt (2018) para describir a Bad Bunny. Ansermet (2014) manifiesta que esta categoría se ha empleado para caracterizar a las personas que exploran los géneros, sin necesidad de "detenerse" en uno. Por ejemplo, son aquellos hombres que usan prendas o accesorios catalogados como "feminizados"; o bien, a la inversa. Este término, en conjunto con el género, la masculinidad hegemónica y la teoría queer, se aborda desde los elementos visuales presentes en los videos de las canciones seleccionadas, puesto que en las letras no se hace referencia verbal o explícita.

\section{Metodología}

La investigación se desarrolló durante el período junio de 2019 a marzo de 2020, y su objetivo general fue analizar los discursos sobre el género expuestos en las canciones de Bad Bunny. Este estudio es de corte cualitativo. Según Monje (2011) este tipo de investigación se caracterizan por ser: a) inductiva: parte de información para construir marcos teóricos, b) holística: se ubica en múltiples escenarios, al contemplar las personas en su contexto, c) naturalista: interactúa con informantes de modo natural a través de técnicas de conversación, d) descriptiva: centra su análisis en la descripción de los fenómenos y e) comprensiva: emplea la descripción para comprender críticamente la realidad social. En este caso, se considera que lo cualitativo orienta el proceso, pues la intención no es cuantificar ni generalizar la información, sino profundizar en interpretaciones subjetivas.

En lo que concierne a la técnica de recolección de información y dato se empleób la netnografía, cuyo fin se relaciona con "la indagación y la comprensión de las interacciones e interrelaciones sociales generadas en Internet, como respuesta a la intermediación tecnológica [...] pretende entronizarse como medio y recurso de estudio" (Turpo, 2008, p. 83-84). Por tanto, la netnografía se interesa por estudiar las interacciones sociales, de carácter virtual, como una forma de construcción de discursos y visiones culturales. Se incluye dicha técnica porque, en el proceso de estudio de los videos seleccionados, también se abordan, a grandes rasgos, las 
reacciones y los comentarios publicados por parte de las personas usuarias de Youtube, Facebooky Twitter.

En el análisis de los videos se incorporan insumos de la propuesta metodológica planteada por Aguaded y Rodríguez (2013). Estos autores proponen tres etapas: a) segmentación: se ahonda en la estructura de la canción; b) análisis videográfico: se estudian los códigos del análisis formal del video musical (visuales, gráficos, sonoros y sintácticos), los códigos del análisis de la representación (puesta en escena, espacio videográfico y tiempo videográfico) y los códigos del análisis de la narración (existentes y acontecimientos); y c) interpretación: se enfoca en la relación con el objeto de estudio, tanto a nivel externo como interno. En este caso, el abordaje se delimita al segundo y tercer momento, con el fin de captar el mensaje evidente y el subyacente.

La muestra estudiada se conforma por los siguientes videos: Soy peor (2016), Mía (2017), ¿Quién tú eres? (2018) y Yo perreo sola (2020). Asimismo, se revisaron las letras de las 53 canciones que fueron lanzadas desde el 2016 hasta marzo de 2020, ya sea que formen parte de un álbum o sean independientes, en donde Bad Bunny figura como artista principal, excluyendo los temas en que es invitado. De las canciones se extraen fragmentos relacionados con los tópicos de discusión.

Por último, alusivo a la técnica de análisis de resultados se seleccionó el Análisis Crítico del Discurso (ACD), el cual se "centra en el análisis discursivo y estudia, principalmente, la forma en la que el abuso de poder y la desigualdad social se representan, reproducen, legitiman y resisten en el texto y el habla en contextos sociales y políticos" (Van Dijk, 2016, p. 204). Este método se ha considerado como un movimiento social y discursivo comprometido a nivel ético y político. En este proceso investigativo, este compromiso se asume para estudiar los mensajes evidentes y, al mismo tiempo, indagar en los elementos que subyacen, es decir, lo que se dice de formas no explícitas.

\section{Bad Bunny: masculinidades y violencia contra las mujeres}

El primer video que se analiza es Soy peor (2016). Tiene una duración de 4:29 minutos. En cuanto a la estructura de los acontecimientos, se puede dividir en tres momentos: a) dubitativo: el ambiente es sombrío, la música suena bajo, la cajuela del auto se encuentra abierta y dentro de ella hay una persona con las manos atadas y una bolsa en su cabeza; b) travesía: en este punto, la narración se realiza cronológica y psicológicamente, el cantante añora y recuerda las experiencias que lo llevaron a realizar su viaje; y c) ruptura-desenlace: el protagonista de la canción llega a su destino cuando se da cuenta que superó su "versión anterior". Esto se simboliza a través de la quema de dos tablas, que marcan una equis, detrás de él.

La vestimenta del cantante tiene tres diseños: a) camisa de diseños floreados y pantalón negro b) camiseta y pantalón negros, abrigo y gorro; y c) camiseta y pantalón negros. En ninguno de los tres conjuntos de vestimenta de Bad Bunny se identifican elementos asociados del "género fluido". Al contrario, las apariencias que proyecta se 
asocian con la rudeza, la violencia, la seducción y la conquista de mujeres. El hombre pasa a ser el centro de la acción y las mujeres la periferia.

El segundo vídeo corresponde a Mía (2017), también dirigido por Fernando Lugo. Su duración es de 3:30 minutos. Esta canción es interpretada junto a Drake (Canadá, 1986). Los momentos de esta canción se agrupan en: a) inserción al ambiente: los protagonistas ingresan a una fiesta realizada en el patio de una casa que tiene la bandera de Puerto Rico; b) clímax: se genera un ambiente de frenesí en la fiesta, en donde hay mujeres bailando alrededor de los hombres y consumo de bebidas alcohólicas; y c) quietud: el nivel de la fiesta baja y se genera una atmósfera de mayor tranquilidad. Se podría afirmar que esto último sucede debido al consumo de drogas o sustancias tranquilizantes, lo cual se visualiza a lo largo de toda la narrativa del video.

En esta canción, Bad Bunny lleva dos vestimentas: a) overol de rayas negras y amarillas; y b) camiseta negra y pantalón de rayas. En el minuto dos del video se observa que el pantalón mencionado es la parte inferior del overol, por lo que termina siendo el mismo conjunto. Uno de los rasgos de la apariencia física sobresaliente es que el artista lleva las uñas pintadas color negro. El esmalte de colores en las uñas ha sido uno de los mandatos de género impuestos a las mujeres, y prohibidos a los hombres. En los videos, las presentaciones y las actividades de premiación este artista ha llevado sus uñas pintadas; incluso en algunos casos ha utilizado postizas. Se podría deducir a primera vista que el autor rompe esquemas simbólicos.

El tercer vídeo es ¿Quién tú eres? (2018), fue dirigido por Fernando Lugo y Bad Bunny. Su duración es más extensa que los dos anteriores, 5:11 minutos. Se divide en tres momentos: a) intromisión al espacio de conquista y poder masculino: Bad Bunny y su amigo ingresan al bar que representa un escenario de masculinidad, en donde son otros hombres, los motociclistas, quienes ejercen su dominio; b) travesía: al igual que en Soy peor (2016), el artista emprende un viaje, esta vez en un tráiler, en donde son interceptados por los motociclistas y se enfrentan en el camino; y c) culminación: la narración termina cuando Bad Bunny y su acompañante enfrentan físicamente a dichos motociclistas. En ese instante, se abre la compuerta trasera del tráiler y sale Steve Austin (Estados Unidos, 1964), ex luchador libre, a golpear y "vencer" a los contrincantes del conejo.

La vestimenta de Bad Bunny se conforma por dos atuendos: a) apariencia de cowboy, o vaquero, con lentes de sol y chaqueta de franela; y b) abrigo de cuadros blancos y negros, y un gorro. Es importante tomar en cuenta que la figura del vaquero ha sido medular dentro del género de películas western ${ }^{3}$. De acuerdo con Sánchez (2016), el cowboy se proyecta como un hombre masculino, heteronormado, blanco, valiente, estoico, que está dispuesto a exacerbar la violencia. No obstante, esta figura no solo se encuentra en las películas estadounidenses, pues también ha estado presente en el cine mexicano, especialmente en la comedia ranchera, que estableció una supremacía machista basada en la seducción, el consumo del alcohol y el desafío (Feasey, 2008).

${ }^{3} \mathrm{El}$ western es un género cinematográfico ambientado en el Viejo Oeste estadounidense. Del mismo modo, se encuentran textos literarios catalogados como literatura de vaqueros 0 literatura del oeste (Tresánchez, 2011). 
Núñez (2017) manifiesta que la presencia del personaje varón usando ropa "vaquera" en todos los espacios públicos se articula con una propuesta ideológica de masculinidad hegemónica y, al mismo tiempo, se muestran como representantes del pasado agonístico. Además, condensa una serie de representaciones sociales arquetípicas construidas desde el patriarcado y el capitalismo: macho y burgués. En Costa Rica, la figura del vaquero ha sido uno de los referentes en la masculinidad hegemónica, debido a su vinculación con la actividad económica de la ganadería y su asociación con los topes, práctica cultural cuestionada desde diferentes puntos de vista y argumentos. Según Quesada (2007) el tope consiste en un "desfile de caballos celebrado en alguna fiesta popular" (382). Históricamente, los topes se han convertido en un espacio donde se representa la masculinidad dominante y se marca la estratificación de clases, es un alarde del poder adquisitivo.

En el video mencionado, Bad Bunny no solamente utiliza una vestimenta que representa un arquetipo de la masculinidad hegemónica, sino también ejerce las actitudes y comportamientos supeditados a dicho arquetipo, que se resumen en la siguiente tríada: violencia-licor-virilidad. Desde el título: ¿Quién tú eres?, se percibe la arrogancia del cantante al invalidar a su receptor. En este caso, interpela a un hombre: “¿Quién tú eres? / Dime, socio, ¿quién tú eres? / Para frontearme a mí, ¿quién tú eres?” (¿Quién tú eres?, Bad Bunny, 2018). Él considera que el receptor no tiene la facultad para enfrentarlo. La actitud intransigente ha sido recurrente en este artista, como se aborda más adelante.

El último video estudiado es Yo perreo sola (2020), dirigido por Bad Bunny y Stillz. La duración es de 3:20 minutos. Para analizar este video, inicialmente se incorpora el concepto de cronotopo, planteado por Bajtín (1989), que refiere a la intervinculación esencial de las relaciones temporales y espaciales. Si bien es cierto el autor aporta esta categoría a los estudios literarios, especialmente en las novelas, su uso permite definir la estructura del video y los acontecimientos identificados, que se segregan de la siguiente forma: a) preludio: se contextualiza en la habitación de un adolescente (Benito) ambientada en los años noventa 5 : videojuegos, decoración y cintas VHS (Video Home System); b) liberación: inicia con Bad Bunny bailando; c) centralización: el cantante pasa a ser el centro de atención; en una escena el artista "perrea con él mismo" en apariencia feminizada y masculinizada; y d) reflexión: concluye con la participación de diferentes mujeres bailando. Se lee la frase: "Ni una menos" en luces neón de color verde en una pared; finaliza con el siguiente mensaje: "Si no quiere bailar contigo, respeta, ella perrea sola".

En cuanto a la vestimenta y el aspecto físico, el cantante presenta siete apariencias: a) traje (blusa, falda corta y botas con tacones) ajustado de color rojo, cabello largo y negro, pestañas postizas, maquillaje y accesorios feminizados; $b$ ) enterizo con estampado de flores, cabello largo y negro, implantes grandes en los senos y maquillaje más sutil; c) camiseta, abrigo y lentes rosados, junto con un sombrero de color verde; d) camiseta y pantalón negros, y cadenas de oro; e) cabello

\footnotetext{
${ }^{4}$ Cuando se habla de ropa vaquera se refiere al siguiente atuendo: camisa de manga larga (mayoritariamente de cuadros), pantalón de mezclilla, botas de cuero, hebilla grande en la faja y el sombrero.

${ }^{5}$ El mismo escenario se observa en Safaera (2020). Además, el adolescente también sale en los videos Bichiyal (2020), Pero ya no (2020), Ignorantes (2020), La difícil (2020) y Si veo a tu mamá (2020), junto con la portada del disco.
} 
largo y rubio, blusa y pantalón negros, boina y tacones; f) sin camiseta, falda larga tipo escoses y collar con puntas; y g) camisa y pantalón blancos, y una gorra. A partir de los parámetros establecidos sobre el género, se puede afirmar que el vestuario a), b) y e) se catalogan como feminizados; d) y g) son masculinizados. En el caso de las vestimentas c) y f) transitan entre esta dicotomía.

\section{Entre lo queer, lo drag y los cuestionamientos al género}

Este video ha sido una de las producciones de Bad Bunny que ocasionó más revuelo en redes sociales. Fue publicado el 27 de marzo en Youtube, en menos de semanas obtuvo casi 85 millones de reproducciones. Algunos medios de comunicación y usuarios de redes sociales6 rescatan la intención de Bad Bunny en cuanto a la deconstrucción de los patrones de género:

"Está haciendo drag, no me parece que esté haciendo comedia. En realidad, lo que está haciendo es abogar por el respeto y la inclusión" (Mariela, 4 de abril de 2020, Facebook).

"Me parece que Bad Bunny al vestirse de mujer desafía toda la masculinidad frágil de muchos machitos que se escandalizaron con ello, no es la mejor canción pero ya dejemos de ofendernos por esto cuando desde los años 70-80 hay géneros musicales como el glam, de hombres que ya tienen este tipo de estilo" (Julie, 1 de abril de 2020, Youtube).

"[...] envió un contundente mensaje de respeto a la comunidad drag. Y es que sí Bunny se vistió de Drag Queen" (El Heraldo de México, 27 de marzo de 2020, Internet).

Se destacan dos aspectos: a) lo drag queen y b) otras bandas que han transgredido el género. El video ha obtenido casi tres millones de "me gusta", y tres cientos mil "no me gusta". Lo anterior permite deducir a grandes rasgos que la mayoría de las personas que han reproducido el video aprueban su contenido y mensaje, o bien, les agrada los elementos circunscritos en la producción: la música, la escenografía o el vestuario. Los comentarios con más apoyo de otros usuarios son aquellos que ven positiva la "intención" del cantante.

En segundo lugar, en dos comentarios citados se afirma que Bad Bunny en el video de Yo perreo sola (2020) hace drag, o se representa visualmente como drag queen. Otros comentarios manifiestan que lo que hace es transformarse: "Bad Bunny se transforma en mujer para el video de "Yo perreo sola»" (El nacional, 30 de marzo de 2020, Internet). Es oportuno contemplar que las categorías "drag queen" y "transformista", mantienen diferencias entre sí. El dragqueenismo, como lo denomina Villanueva (2014), consiste en una práctica de carácter político y estético basada en el trabajo de representación de la realidad. Horowitz (2012) añade que dicho movimiento simboliza el tejido que conecta lo político y lo performativo; relacionándolo con la idea de la performatividad del género planteada por Butler (2006) dentro de la teoría queer.

\footnotetext{
${ }^{6}$ En los comentarios publicados por usuarios de las redes sociales, se coloca únicamente el primer nombre, sin apellido. Cuando las opiniones se extraen de videos, se menciona el nombre del canal de Youtube. En el caso de las noticias, se menciona el nombre del medio. En todos los comentarios se aclara la fuente: Facebook, Youtube, Twitter o Internet.
} 
El artista Drag construye una obra principalmente desde las técnicas del cuerpo, usando accesorios, vestuario y una teatralidad exagerada como herramientas que buscan subvertir los códigos del género, en una propuesta estética y de performance que busca redefinir la identidad a través de la sátira. (Castillo, 2014, p. 8)

Vencato (2005) clasifica la práctica drag queen en tres grupos: a) quienes se identifican con su personaje y lo expresan en su vida cotidiana, b) quienes se diferencian del personaje, pero siguen siendo reconocidos por sus actuaciones, más allá de los escenarios; y c) aquellas personas que se separan del personaje, tanto en los espectáculos como en el ámbito personal. Las drag queen7 crean y asumen un personaje-figura a quien le asignan nombre, apariencia física, rasgos en sus personalidades, entre otros elementos que configuran su identidad. En muchos casos, las representaciones drags se establecen mediante la exageración de los rasgos feminizados8: excesivo maquillaje, pelucas, uso de tacones altos, empleo de corsés; tal y como se observa en el programa televisivo RuPaul's Drag Race (2009actualidad), presentado por RuPaul Charles (Estados Unidos, 1960). Este show ha producido 16 temporadas hasta el momento en que se finalizó este artículo.

Por otra parte, el transformismo es cuando las personas transgreden sus géneros impuestos con un propósito determinado, que puede ser artístico o político (García, 2013). A diferencia del drag queen, el transformismo suele representar un personaje famoso. Sin embargo, no elimina la posibilidad de que los intérpretes diseñen sus propios personajes. En Costa Rica, comediantes hacen "transformismo humorístico". Dos ejemplos son Norval Calvo Chacón (1970) y Edson Picado Castro (1997), quienes imitan a personalidades de la política, el entretenimiento y el deporte. Roque Ramírez Arce (1976) creó un personaje llamado Doña Merry, que ha tenido una gran aceptación del público.

Un comediante, quien trabajó junto a Norval Calvo, que también se transformaba en sus representaciones, fue Froilán Bolaños Coto (Costa Rica, 19542009). Él imitaba a Gloria Valerín Rodríguez (Costa Rica, 1955), ex diputada. En las imitaciones, Bolaños solía absurdizar las posturas feministas de Valerín, quien desde hace más de veinte ha luchado por los derechos de las mujeres en Costa Rica. En uno de los shows, mientras imitaba a Valerín, exigió que en las corridas de toros hubiese vacas para que existiera igualdad. Cuando salía al escenario, reproducían una canción que decía: "Gloria, Gloría Valerín, peleona hasta el fin". Para el artista, las exigencias de las feministas se reducían a aspectos irracionales y sin sentido. Esto lleva reflexionar que no todas las prácticas transformistas, en donde los hombres se visten feminizadamente, son prácticas éticas y políticas, ya que se pueden emplear para ridiculizar a las mujeres y violentarlas.

\footnotetext{
${ }^{7}$ Feministas han cuestionado las representaciones de las drag queens al afirmar que caen en absurdización e hipersexualización de las mujeres. Desde esta idea, el programa de Rupaul se ha interpelado porque sus participantes cuando se encuentran haciendo drag, reproducen las conductas competitivas impuestas a las mujeres. Para ellos "vestirse" de mujeres requiere ser sabotearse entre sí. Además, Rupaul manifestó que las personas trans ni las mujeres pueden hacer drag (Zapata, 2018); él cree que transgredir las normas genéricas es una reivindicación exclusiva para hombres.

${ }^{8}$ No todos los drag queens representan la exageración de lo feminizado. Conchita Wurst (Austria, 1988) ganó el Festival Eurovisión en el año 2014. Esta artista se ha autodenominado como drag, género fluido y queer.
} 
En tercer lugar, Bad Bunny no es el primer cantante que asume una apariencia feminizada en un video musical. En 1984, la banda inglesa Queen (Inglaterra, 1970), mostró a sus cuatro integrantes transformados: Freddie Mercury (Zanzíbar, 1946Inglaterra, 1991), Brian May (Inglaterra, 1947), Roger Taylor (Inglaterra, 1949), y John Deacon (Inglaterra, 1951), en la canción I want to break free (1984)9. El video parodia a la serie televisiva Coronation Street (1960), novela exitosa en el Reino Unido. A lo largo de los acontecimientos presentados, los cantantes reflejan la opresión enfrentada por las mujeres en el ámbito doméstico. Esta producción audiovisual se puede analizar desde las categorías: parodia y carnaval, planteadas por Bajtín (1989). Ambas parten de la idea de subvertir los valores hegemónicos a través de la ironía y la risa, cuyo fin es desestabilizar las reglas que regulan la convivencia social y han sido percibidas como incuestionables. La canción de Queen se ha considerado un himno por parte de la comunidad sexualmente diversa.

De igual manera, existen subgéneros musicales que también se han convertido en espacios de denuncia y reivindicación de las masculinidades diversas. El glam rock es una corriente del rock desarrollada durante la primera mitad de los años setenta, principalmente en los países anglosajones, que englobaba a artistas y bandas caracterizadas por la diversidad en sus propuestas sonoras (Arenillas, 2016). Dentro de dicha corriente sobresalen el cantante David Bowie (Inglaterra, 1947-Estados Unidos, 2016), y las bandas T.Rex (Inglaterra, 1967-1977), Roxy Music (Inglaterra, 1971-2014) y New York Dolls (Estados Unidos, 1971-1975). El estilo era extravagante, colorido y andrógino10, ya que la intención era enviar un mensaje de resistencia ante la subordinación simbólica ejercida por los grupos dominantes, en donde privaba la idea de una masculinidad hegemónica: violenta, viril, oscura, sin sentimientos (Gregory, 2002), legitimada por el rock metal, a pesar de que este género se consolidaba como una propuesta anticapitalista.

A partir de lo señalado hasta este punto, surgen una serie de interrogantes: ¿Bad Bunny realmente hace drag en Yo perreo sola?, ¿se puede afirmar que este video es una representación desde el transformismo? ¿La intención es parodiar, es decir, intenta subvertir los valores promovidos en alguna referencia específica? Sobre la primera pregunta, si se revisan los aportes teóricos citados, no se podría concluir que sea dragqueenismo, pues en la mayoría de los videos el artista muestra una apariencia masculinizada; en muchos, configurada desde la masculinidad hegemónica: rodeado de muchas mujeres que representan objetos sexuales para su disfrute y placer. Si bien es cierto en dos canciones: Caro (2018) y Solo de mí (2018), las protagonistas han sido mujeres, solamente en un video, de los 34 que ha producido, mantiene una apariencia "transgresora". Al no ser la generalidad en su espectáculo como artista, no se podría afirmar que sea drag queen, o intente serlo.

${ }^{9}$ Ronald Reagan (Estados Unidos, 1911-2014), ex presidente estadounidense (1981-1989) prohibió la reproducción de este video en territorio norteamericano. Se transmitió hasta 1991. Según él, promovía la homosexualidad en la población.

10 "La androginia se entiende como un patrón de conducta que permite a los individuos expresar todo el conjunto de emociones y de posibilidades asociadas con los roles sexuales, sin atender a estereotipos sexuales [...] El movimiento andrógino, gracias al impulso de los movimientos feministas, principalmente, surgió como un intento de respuesta ante la bipolaridad genérica de lo masculino y lo femenino" (Cardona, 2003, p. 1-2). 
Para la segunda pregunta, se debe retomar la premisa de que el transformismo se consolida a partir de la representación o creación de un personaje icónico, por lo que tendría que revisarse si alguna de las tres apariencias feminizadas presentes en Yo perreo sola (2020), remite apersonas específicas, o más bien se pueden concebir como "alter egos" creados por el cantante. En este artículo no se descarta que el transformismo se pueda realizar una sola vez, no obstante, se considera que esta práctica cuando se realiza con el fin de cuestionar los parámetros de "normalidad" impuestos, debe estar fundamentada desde su dimensión política y ética. Dicha dimensión se fortalece a partir de la experiencia, la reflexión y la autocrítica por parte del artista. Se torna esencial que los artistas mantengan una apertura a recibir comentarios y apreciaciones.

La última interrogante conlleva a otra pregunta conexa: ¿Qué parodia Bad Bunny? En el caso de I want to break free (1983), la banda parodió los roles de género presentes en una serie de televisión. Sin embargo, en el video analizado no se identifica el objeto parodiable. Cuando Bad Bunny sale bailando con los senos descubiertos y su mano cubriéndolos, ¿qué desea subvertir? Como se ha señalado, hay autores y autoras que manifiesta que este cantante ha intentado romper la masculinidad hegemónica: "ir en contra de la norma, de lo establecido y continuar rompiendo esquemas" (Platt, 2018, p. 9). Aunado a esto, comentarios en redes sociales arguyen que: "Bad Bunny no se ha «disfrazado» de mujer, ni ha representado a una mujer trans11... Más bien ha cuestionado los cánones de belleza masculinos haciendo drag" (Pablo, 30 de marzo de 2020, Twitter).

Si el verdadero objetivo de Bad Bunny se relaciona con revertir los cánones de belleza masculina, interpelar los arquetipos construidos por la masculinidad hegemónica, o parodiar la forma tradicional en cómo se representan las mujeres en la música, también debería enfocarse en cuestionar la cosificación y la objetivación del cuerpo de las mujeres en el trap, ya que esta matriz ideológica y sexista también ha estado latente en sus videos: Chambea (2017), Tú no metes cabra (2017), Ni bien ni mal (2018), La difícil (2020), Ignorantes (2020), solo por mencionar algunos ejemplos. De igual modo, se ha evidenciado a lo largo de sus letras:

"Y joderme por todos los culos que tengo en el celular" (Soy peor, Bad Bunny, 2016); "Tu culo pégalo cerca para retumbarte completa" (Diles, Bad Bunny, 2016); "'Estás culona, flow rikishi [...] Que todos los culos se quemen [...] Te pongo el toto a flotar" (200 MPH, Bad Bunny, 2018); "Yo sé que ese culo es caro" (Caro, Bad Bunny, 2018); "Yo quiero ser tu daddy, para darte gasolina / El culo grande y el traje chiquito" (Cuidado por ahí, Bad Bunny, 2019); "Y todos los culos de Miami explotándome el cel" (A tu merced, Bad Bunny, 2020), "Pero esas tetas son C [...] Tienes un culo cabrón" (Safaera, Bad Bunny, 2020).

En octubre de 2019, Bad Bunny se presentó en los "Pornhub Awards", premiación enfocada en la industria pornográfica. Un sector del feminismo ha insistido en que "la pornografía no sólo refleja la dominación sexual patriarcal, sino que, principalmente, la refuerza [...] es un elemento clave en la producción y reproducción de las relaciones sociales jerárquicas y violentas" (Solana, 2013, p. 167). Bajo esta

${ }^{11}$ Bad Bunny se presentó en The Tonight Show With Jimmy Fallon con una camiseta que decía "Mataron a Alexa. No a un hombre con falda", denunciando el transfeminicidio (Heim, Ruf y Ayelén, 2018) de Alexa, mujer transgénero asesinada brutalmente en Puerto Rico. 
misma idea, la pornografía implica un contrato social y legal respecto al derecho de los hombres sobre las mujeres, que reafirma su poder masculino y viril. Por tanto, la pornografía se convierte en un mecanismo de consumo que perpetúa la desigualdad, las representaciones degradantes, la mercantilización y cosificación del cuerpo de las mujeres. A su vez, simboliza uno de los espacios que el patriarcado y el capitalismo ha consolidado como uno de sus nichos.

El 8 de marzo de 2020, Día Internacional de la Mujer, este cantante publicó: "En vez de felicitarla, respétela. Respeta sus capacidades, sus virtudes, sus defectos, respeta su espacio y su tiempo, sus deseos, sus metas, sus sueños, sus luchas, respeta su cuerpo y cada una de sus decisiones. Hoy y todos los días, feliz día de respetar a la mujer" (Bad Bunny @sanbenito, 8 de marzo de 2020, Twitter). Resulta contradictorio que un cantante que aboga por respeto al cuerpo de las mujeres e incluye consignas feministas cante los siguientes extractos: "Terminar en la cama amarrada [...] Como media vida, media asfixiada" (Bichiyall, Bad Bunny, 2020), y "Ahora te lo meto yo, y ese totito tú manchas" (Te lo meto yo, Bad Bunny, 2017). Las posiciones ambiguas y relativizadas también se observan en algunas publicaciones: "El disfraz puede ser una reducción o una burla pero también una reivindicación o una forma de empatía, según se lea" (Maldonado, 2020, párr.7). Si bien, cada persona crea su criterio, las realidades de desigualdad demandan tomar una postura.

Dentro de los comentarios estudiados en redes sociales, existen personas que establecen una separación entre la identidad de género y la violencia contra las mujeres: "[...] creemos que este video no es sobre identidad de género, el video es sobre autonomía de las mujeres en la pista de baile" (Las Igualadas, 31 de marzo de 2020, Youtube). Ante esta perspectiva, es pertinente reiterar que el sexismo es el sistema de dominación en que se cimienta la opresión de las mujeres, la masculinidad hegemónica y la violencia hacia la población sexualmente diversa, a través de la misoginia, el machismo y la diversofobia. Este sistema se basa en la jerarquización de la vida social a partir del sexo como factor determinante, lo que provoca una atribución de valoraciones y significados, "ordena la realidad en dos cajones que respectivamente se señalan "esto es lo femenino", "esto es lo masculino»" (Morgade, 2001), y concede privilegios a los hombres.

Segregar el tema de la identidad de género, enmarcado dentro de la diversidad sexual, y los derechos de las mujeres, es una visión reduccionista y descontextualizada de las múltiples formas en cómo opera el sexismo en la vida cotidiana. Desde esta visión deshistorizada, muchas veces se destacan las acciones de grupos políticos que han abogado, en el plano formal, por un "reconocimiento" de los derechos de las mujeres; pero siguen reproduciendo discursos en contra las garantías de las personas sexualmente diversas. En caso contrario, lo mismo sucede con los hombres homosexuales que han luchado por el matrimonio igualitario y por políticas de inclusión y la validación de sus derechos; no obstante, criminalizan la protesta feminista, emplean adjetivos como "feminazis", se oponen al derecho a decidir de las mujeres y comparten imágenes en sus redes sociales que dicen: "estudia para que no creas que rompiendo las cosas, se cambia la historia".

El movimiento feminista, a partir de la segunda ola en la década de los setenta, y el movimiento de diversidad sexual como expresiones de los nuevos movimientos sociales (Touraine, 1995) han desempeñado su praxis política de manera articulada, al 
resistir ante el mismo sistema de dominación: sexismo, y en un contexto en común: patriarcal. Por consiguiente, cuando se estudian los discursos respecto a la transgresión o reproducción de las normas de género legitimados en los productos socioculturales, debe profundizarse cómo se representan las mujeres; puesto que enfocarse en un solo aspecto es fragmentar la lucha. Vale aclarar que estos análisis críticos deben encauzarse desde una visión holística, en donde también se interpelen los discursos clasistas, racistas, colonialistas, xenófobos, etnófobos, o cualquier otro basado en la violencia y la explotación.

Del mismo modo, el abordaje de los discursos de género en la música no se puede desarrollar desde una perspectiva comparativa, es decir, enfocarse en quien es más sexista: "en comparación con otros exponentes, el discurso de Bad Bunny ha mostrado ser diferente, que rompe barreras y rechaza estereotipos recurrentes, y su popularidad extrema es muestra de ello" (Platt, 2018, p. 9). Los sistemas de dominación se deben cuestionar independientemente del "grado" en que se presenten y sin importar quien los materialice, ya que se modifican las expresiones en cómo se operacionaliza esa desigualdad, que en todos los casos oprime a otra persona 0 grupo.

Si el video de Yo perreo sola (2020) se percibe como una propuesta concientizadora, política y reflexiva, es fundamental identificar las contradicciones en ese mismo artista para evitar caer en idealizaciones que no permiten ahondar desde posturas críticas. Días después de estrenar esta producción audiovisual, Bad Bunny publicó el siguiente mensaje en sus redes sociales: "tengo respuesta a todas tus preguntas, y defensa para todas tus acusaciones, pero... quien puñeta tú eres?? Ni que fueras mi mamá pa' darte explicaciones bye" (Bad Bunny @sanbenito, 27 de marzo de 2020, Twitter). Esta opinión refleja su intransigencia al no aceptar críticas, incluso de mujeres feministas y de la comunidad sexualmente diversa que se supone tienen protagonismo en el video. Al mismo tiempo, se cree dueño de la razón y invalida a quienes no coinciden con él; ninguna persona puede interpelarlo 0 "encararlo", así como sucede en ¿Quién tú eres? (2018).

Cuestionar la masculinidad hegemónica no requiere ni debe ridiculizar lo femenino. El propósito ético y político de la teoría queer no consiste en violentar a un grupo para reivindicar los derechos de otro sector. Quien reproduce discursos en detrimento de las mujeres para reivindicar garantías de la comunidad sexualmente diversa, cae en lecturas patriarcales y sexistas de dicha teoría, ya sea consciente 0 inconscientemente. En esta misma línea, las representaciones en el dragqueenismo y el transformismo tienen que desarrollar un ejercicio de introspección orientado por las siguientes interrogantes: ¿cómo deseo proyectar a las mujeres? ¿cuál es el fin de la puesta en escena? ¿cuál es el aporte de mi espectáculo a la sociedad? Esto debido a que, al no existir una reflexión previa se reproducen prácticas permeadas por visiones opresoras: "Lo que no me termina de encajar es la hipersexualización. Bad Bunny dice: "me voy a disfrazar de mujer, pero porfa pónganme chichotas y tacónsotes»" (Que Fish TV, 29 de marzo de 2020, Youtube). 


\section{Conclusiones}

Para concluir, es pertinente esclarecer dos elementos. En primera instancia, la música no puede concebirse únicamente como un producto sociocultural de placer, disfrute y entretenimiento, ya que puede materializar universos discursivos que abogan por el mantenimiento del poder asimétrico y jerarquizado. Así como también hay letras de canciones que cuestionan y polemizan la realidad sufrida por diversos grupos poblaciones históricamente vulnerabilizados. La música no se libra del entramado social y cultural en que se circunscribe, al contrario, se encuentra atravesada y permeada por dicho contexto. Por consiguiente, es tarea fundamental de quienes analizan la música partir de una mirada crítica, que profundice en las premisas subyacentes, que suelen ser invisibilizadas en muchos de los abordajes.

En segunda instancia, este artículo no intenta censurar ni idealizar géneros musicales o artistas. Se propone una politización de lo que escuchamos y vemos, en donde la discusión no se reduzca al argumento de que en todas las creaciones se encuentran rasgos de los sistemas de dominación. Se apela a generar una conciencia que propicie las herramientas para encauzar perspectivas que logren trascender lo evidente. Junto a esto, es fundamental reconocer los avances generados y, a su vez, los desafíos que quedan pendientes. Así como un artista puede promover discursos en contra de la xenofobia, existe la posibilidad de fomentar visiones homofóbicas. Esas contradicciones deben ser identificadas con el fin de no repetir los esquemas de pensamientos impuestos y las visiones de mundo creadas desde los grupos de poder hegemónico.

En el caso estudiado respecto a Bad Bunny, este cantante tiene una intención aparente en donde "apela a una deconstrucción de los mandatos de género y promover la autonomía de las mujeres" plasmada en su canción Yo perreo sola (2020), como en sus declaraciones, sus vestimentas en actividades públicas y sus mensajes en redes sociales. No obstante, a pesar de incorporar consignas feministas, o transgredir el género, al mismo tiempo violenta a las mujeres en el mismo álbum. Por consiguiente, se manifiesta que no contribuye a la transformación social; más bien se apropia de luchas para mercantilizarlas y lucrar con ellas, lo cual resulta completamente interpelable.

Por último, se coincide con los planteamientos de Verdú y Briones (2016), quienes aluden a la necesidad de transformar los referentes culturales que fomentan la naturalización y reproducción del sexismo. Para esto, es central creer en la construcción de una sociedad diferente, basada en la equidad y la justicia social. Este compromiso se debe evidenciar por parte de los artistas, al momento de producción, y de las personas que consumen dichas producciones. Es necesario reiterar que lo personal es político, así como las representaciones en los productos socioculturales también lo son. Quienes creemos en la utopía de una sociedad diferente debemos seguir interpelando nuestro contexto con el fin de alcanzar una ruptura paradigmática. Mientras el patriarcado, el sexismo y el capitalismo continúen siendo sistemas de dominación estructurales, las lecturas feministas deben seguir develando la desigualdad sistemática y, a su vez, incomodando a los grupos de poder. 


\section{Bibliografía}

Aguaded, José \& Rodríguez, Jenifer (2013): "Propuesta metodológica para el análisis del vídeo musical”, en Quaderns del CAC,Vol.XXVI, No. 39, p.63-70.

Ansermet, François (2014): "Elegir el propio sexo: Usos contemporáneos de la diferencia sexual", en Revista Virtualia, Vol. XXIX, No. 11, p.1-9.

Araya, Sandra (2003): "Relaciones sexistas en la educación”, en Educación,Vol. XXVII, No. 1 , p.41-52.

Arenillas, Sara (2016): "Retromanía, artificio y transgresión del glam en la música popular española del siglo XXI", en Cuadernos de Música Iberoamericana, Vol XXIX, No.1, p. 163-183.

Bajtín, Mijaíl (1989): Teoría y estética de la novela. Madrid: Taurus.

Berrocal, Emilio \& Gutiérrez, José (2002): "Música y género: análisis de una muestra de canciones populares", en Revista Científica de Comunicación y Educación, Vol. XVII, No.4, p. 187-190.

Bravo, Nazareno (2018): "Música e identidades juveniles. El trap como fenómeno global de juventudes marginalizadas", en: III Bienal Latinoamericana y Caribeña de Infancias y Juventudes. Universidad de Manizales, Caldas.

Bravo, Nazareno \& Greco, Emilia (2018): "La elaboración de identidades mundializadas a través del trap. Marginalidades juveniles, consumismo y experiencia musical", enRevista Música e Investigación, Vol. XXV, No.1, p. 45-69.

Briones, Érica \& Verdú, Ana (2016): "Desigualdad simbólica y comunicación: el sexismo como elemento integrado en la cultura", en La ventana, Vol.V, No. 44, p.24-50.

Butler, Judith (2006): Deshacer el género. Barcelona: Paidós.

Cardona, Felipe (2003): “Androginia: ¿Indicador de salud mental?", en Revista Reflexiones, Vol. LXXXII, No.1, p.1-22.

Carrion, Sandy (2018): "7 cosas que debería saber de Bad Bunny si eres un verdadero fan" [On line]. Disponible en: https://larepublica.pe/espectaculos/1336032bad-bunny-lima-7-cosas-debes-fan-rey-trap-puerto-rico-trap/

Castillo, Anabel (2014): "Performatividad y roles de género en lo drag en el escenario quiteño: el Teatro Dionisios”. Tesis (Maestría en Artes). Quito: Universidad Andina Simón Bolívar. 
Connell, Robert (1997): "La organización social de la masculinidad", en Valdés \& Olavarría (comps.): Masculinidad/es. Poder y crisis, p.17-30. Santiago: FLACSO.

Demetriou, Demetrakis (2001): "Connell's concept of hegemonic masculinity: A critique", en Theory and Society, Vol. XXX, No.3, p. 337-361.

Feasey, Rebecca (2008): Masculinity and popular televisión. Endinburgo: University Press.

Fonseca, Carlos \& Quintero, María (2009):“La Teoría Queer: la de-construcción de las sexualidades periféricas”, enSociológica,Vol. XXIV, No.69, p.43-60.

Fullana, Mariela. (2018): "Trap: juicio al fenómeno del momento". [On line] Disponible en: $\quad$ https://www.noticiasdesantiagodecuba.com/trap-juicio-al-fenomenodel-momento/

García, Andrés (2013): "Construcción de los transformistas en el proceso performativo de lo masculino a lo femenino en la ciudad de Pereira, del Departamento de Risaralda. Colombia". Tesis (Licenciatura en Comunicación Social). Pereira: Universidad Tecnológica de Pereira.

Gregory, Georgina (2002): "Masculinity, Sexuality and the visual culture of Glam Rock", en Cultura y communication, Vol. V., No. 2, p.35-60.

Herrera, Irian, Morales, Claudia \& Salas, Soily (2019): "Rol que desempeñan padres, madres o tutores de niños/as que escuchan el subgénero musical trap, en la Escuela Cristal Estelí, período 2018 - 2019". Tesis (Licenciatura en Trabajo Social). Estelí: Universidad Autónoma de Nicaragua.

Horowitz, Katie (2012): "The Trouble with "Queerness": Drag and the Making of Two Cultures". Tesis (Doctorado en Filosofía). Berkeley: University of California.

Lagarde, Marcela (2005): Los cautiverios de la mujer: Madresposas, monjas, putas, presas y locas. Ciudad de México: UNAM.

Leclerc, Axel \& Mella, Matías (2018): "El fenómeno del trap. El nacimiento de un nuevo género urbano". [On line] Disponible en: http://la210.cl/el-fenomeno-deltrap-desde-el-sur-de-estados-unidos-a-la-escena-chilena-parte-1/

López, Irene (2013): "Consideraciones en torno a la canción como objeto de estudio", enJornaler@s Revista científica de estudios literarios y lingüísticos, Vol. I, No. 1, p.1-14.

Luna, María \& Valadez, Gerardo (2018): "Validación de una Escala de Mandatos de Género en universitarios de México", Ciencia UAT, Vol. XII, No. 2, 67-77. 
Maldonado, Lorena (2020): "Bad Bunny se disfraza de mujer en 'Yo Perreo Sola' y abre el debate: ¿misógino o icono feminista?” [On line]Disponible en: https://www.elespanol.com/cultura/20200328/bad-bunny-disfraza-perreosola-misogino-feminista/478202231 $0 . \mathrm{html}$

Manco, Juan (2018): "Elementos de análisis musical macroformal: un acercamiento crítico al concepto de unidad y a las relaciones entre partes componentes, a partir del análisis de cuatro obras conformadas por varias partes 0 movimientos. Tesis (Maestría en Análisis musical). Medellín: Universidad EAFIT.

Molina, Cristina \& Osborne, Raquel (2008): "La evolución del concepto de género. Selección de textos de S. de Beauvoir, K. Millet, G. Rubin y J. Butler", en EMPIRIA. Revista Metodología de Ciencias Sociales, Vol. V, No. 1, p. 147182.

Monje, Carlos (2011): Metodología de la investigación cuantitativa y cualitativa. Huila: Universidad Surcolombiana.

Morgade, Graciela (2001): Aprender a ser mujer. Aprender a ser varón. Relaciones de género y educación. Esbozo de un programa de acción. Buenos Aires: Novedades Educativas.

Núñez, Guillermo (2017): "Masculinidad, ruralidad y hegemonías regionales: reflexiones desde el norte de México", enRegión y Sociedad, Vol. 5, No.1, p.75-113.

Platt, Sarah (2018): "Nociones de género, música urbana y cultura popular: Cómo el fenómeno Bad Bunny está redefiniendo la masculinidad", en: Primer Coloquio sobre hombres y masculinidades. Universidad de Puerto Rico, Río Piedras.

Quesada, Miguel Ángel (2007): Nuevo diccionario de costarriqueñismos. San José: Editorial Tecnológica de Costa Rica.

Ramírez, Jorge (2018): Cómo analizar de todo. Heredia: Editorial Universidad Nacional.

Sánchez, Miguel (2016). “Jerarquía de la masculinidad y su representación audiovisual en la serie Parks and Recreation”, en Anagramas, Vol. 15, No. 29, p.71-88.

Solana, Mariela (2013): "Pornografía y subversión: una aproximación desde la teoría de género de Judith Butler", en Convergencia. Revista de Ciencias Sociales, Vol. 20, No. 62, p.159-179.

Touraine, Allan (1995): Producción de la sociedad. Ciudad de México: Universidad Autónoma de México. 
Revista Punto Género N.․ 15 Junio de 2021

ISSN 0719-0417 / 257-276

Tresánchez, Eva (2011): "La búsqueda en la novela western americana: Bridal Journey (1950) de Dale Van Every, The Searchers (1954) de Alan Le May y True Grit (1968) de Charles Portis". Tesis (Maestría en Literatura). Madrid: Universidad Complutense de Madrid.

Turpo, Osbaldo. (2008): “La netnografía: un método de investigación en Internet”, en EDUCAR, Vol. 42, No.1, p.81-93.

Van Dijk, Teun (1999): El discurso como interacción en la sociedad. Barcelona: Gedisa.

Van Dijk, Teun (2016): "Análisis Crítico del Discurso", enRevista Austral de Ciencias Sociales, Vol. 30, No.6, p.203-222.

Vencanto, Anna (2005): "Fora do armário, dentro do closet: o camarim como espaço de transformação", en Cadernos Pagu, Vol.XXIV, No.1, p.227-247.

Villanueva, Iván (2014): "Poética y política del dragqueenismo limeño: Discursos y performance legitimadores". Tesis (Maestría en Sociología). Lima: Pontificia Universidad Católica del Perú.

Zapata, Isabel (2018): "Drag, feminismo y brillantina: ¿por qué importan las declaraciones transfóbicas de Ru Paul?" [On line] Disponible en: https://www.letraslibres.com/mexico/cultura/drag-feminismo-y-brillantinapor-que-importan-la-declaraciones-transfobicas-rupaul 